\title{
Qualidade industrial de cana-de-açúcar sob irrigação e adubação com zinco, em Tabuleiro Costeiro paraibano ${ }^{1}$
}

\author{
Carlos H. de A. Farias ${ }^{2}$, Pedro D. Fernandes ${ }^{3}$, Hans R. Gheyi $i^{3}$ José Dantas Neto ${ }^{3}$
}

\begin{abstract}
RESUMO
Esta pesquisa foi conduzida em área experimental da Fazenda Capim II (latitude 60 54' 59,88" S, longitude 350 09' 17,86" 0 e altitude de 121,00 m), local izada no Município de Capim, PB. 0 bjetivou-se avaliar os efeitos de lâminas de água de irrigação e níveis de adubação com zinco na cultura da cana-de-açúcar (Saccharum officinarum), cv. SP 79-1011. 0 delineamento experimental foi em blocos casualizados, com três repetições, em esquema fatorial $5 \times 5$; as lâminas de irrigação, aplicadas por um pivô central fixo, se basearam em 25, 50, 75 e 100\% da ETc, mais um tratamento testemunha, sob condições de sequeiro. Os níveis de zinco foram $0,1,2,3$ e $4 \mathrm{~kg} \mathrm{ha}^{-1}$. A qualidade industrial da matéria-prima foi influenciada, diretamente, pela lâmina de água de irrigação aplicada na cultura. À medida que se aumentou a lâmina de irrigação, aumentaram, também, 0 teor de açúcares totais recuperáveis, 0 teor de sólidos solúveis totais (Brixô), a Pol, a pureza e a PCC; no entanto, diminuíram o teor de fibra e o peso do bolo úmido. Não se observou influência dos níveis de zinco estudados sobre nenhum índice de qualidade industrial da cv. SP 79-1011 de cana-de-açúcar.
\end{abstract}

Palavras-chave: Saccharum officinarum, açúcar, pivô central, manejo

\section{Industrial quality of sugar-cane under irrigation and fertilization with zinc in Coastal Table Lands of Paraiba State, Brazil}

\begin{abstract}
This research was conducted in an experimental area of Capim II Farm (60 54' 59.88" S of latitude; 350 09' 17.86" W of longitude and $121 \mathrm{~m}$ of altitude), located in the municipality of Capim, PB. The objectives were to evaluate the effects of five depths of irrigation water and five levels of zinc fertilization on sugar-cane crop (Saccharum spp.), cv. SP 79-1011. The experimental design consisted of randomized blocks, with three repetitions in a $5 \times 5$ factorial scheme; the irrigation depths were: rainfed, 25, 50, 75 and $100 \%$ of ETc. The levels of zinc were: $0,1,2,3$ and $4 \mathrm{~kg} \mathrm{ha}^{-1}$. The industrial quality was influenced by the irrigation depths applied to the crop. The content of total recoverable sugars, the total soluble solids $\left(B r i{ }^{0}\right)$, the Pol, the purity and the PCC increased in proportion with the irrigation water levels; nevertheless, the fiber content and the weight of the humid mass were reduced. The zinc levels did not show any influence on the industrial quality indexes of sugar-cane cv. SP 79-1011.
\end{abstract}

Key words: Saccharum officinarum, sugar, central pivot, crop management 


\section{INTRODUÇÃO}

A cultura da cana-de-açúcar passou a ser considerada, recentemente, uma commodity, valorizada pela capacidade que tem de gerar energia limpa e renovável e de substituir parte da matriz energética global, atualmente centrada na utilização de combustíveis hidrocarbonetos de origem fóssil.

Em nível mundial, começa a haver uma corrida por combustíveis mais 'limpos'. Entretanto, quando o assunto é expandir as fronteiras agrícolas para a produção de biocombustíveis, principalmente o etanol extraido do milho, temem-se os seus reflexos na diminuição de áreas para a produção de alimentos. Essa parece ser uma das grandes vantagens para o Brasil, país de dimensões continentais, dispondo, ainda, de terras para a expansão de cultivo da cana-de-açúcar, além de renovação na extração de etanol uma sustentável fonte de energia combustível.

Em algumas regiões do País, a exemplo do Nordeste e, especificamente, na Paraíba, há interesses em se verticalizar a produção, aumentando a produtividade agrícola e/ou industrial, com melhorias na qualidade da matéria-prima.

Nesse sentido, os produtores paraibanos têm investido, maciçamente, em irrigação e adubação, como principais tecnologias para o aumento de produtividade da cultura de canade-açúcar. Considerando a escassez de recursos hídricos, um dos problemas da expansão da agricultura irrigada no Estado, inclusive no setor sucroalcooleiro, é imprescindível e urgente se estudar práticas de manejo mais eficientes do uso de água; igualmente importante é se identificar os principais problemas de ordem nutricional das plantas, em cada área de produção, visando garantir a sustentabilidade da exploração da cultura.

Na literatura, são variadas as informações sobre demanda hídrica da cana-de-açúcar; segundo Doorembos \& Kassam (1979), a cultura exige entre 1500 e $2500 \mathrm{~mm}^{2} \mathrm{ano}^{-1}$, mas Blackburn (1984) se refere a uma demanda de $1200 \mathrm{~mm}$ anuais. Para Alfonsi et al. (1987), nas áreas canavieiras do Brasil o total de precipitação pluviométrica anual varia de 1100 a $1500 \mathrm{~mm}$ por ano.

Estudando os efeitos da irrigação sobre a qualidade da cana 'CP 65-357, submetida a três níveis de irrigação ( 99,85 e $65 \%$ da fração de esgotamento da água do solo), no Estado do Texas, Wiedenfeld (1995) obteve rendimentos em açúcar de 13,10 e $7,5 \mathrm{t} \mathrm{ha}^{-1}$, respectivamente, sem variar a pureza (87, 86 e 85\%); posteriormente, Wiedenfeld (2000) avaliou diferentes tratamentos de estresse hídrico na cultura, em cinco diferentes estádios de desenvolvimento, registrando reduções de $11 \%$ no rendimento em açúcar, quando a cultura foi submetida ao estresse no período entre 257 e 272 dias após o plantio e de $19 \%$ quando o estresse hídrico ocorreu entre 302 e 347 dias após o plantio. Robertson \& Donaldson (1998) estudaram os efeitos de suspensão da irrigação (drying-off) no período pré-colheita, em 37 experimentos realizados no período de 1966 a 1995, no Sul da África, e constataram que essa prática resulta em aumento de $10 \%$ no rendimento da cana-de-açúcar.

Em condições de Tabuleiro Costeiro paraibano, Dantas Neto et al. (2006) testaram lâminas de irrigação, variando entre 807 e 1343 mm, na cultura de cana-de-açúcar e verificaram comportamento linear positivo sobre as variáveis de crescimento e quadrático para sacarose (POL), com valor de 18,1\% quando as plantas foram irrigadas com $1125 \mathrm{~mm}$. Moura et al. (2005) observaram diferenças em ${ }^{\circ} \mathrm{Brix}$, Pol e PCC em estudos, comparando a cana irrigada com a cana de sequeiro, aumentando 5,00, 10,79 e 8,63\%, respectivamente, quando houve irrigação.

Para aumentar a produtividade, não se pode lançar mão de uma tecnologia em detrimento de outra; a irrigação da canade-açúcar no Nordeste brasileiro, por exemplo, deve ser acompanhada de um plano de nutrição para a cultura, mormente nas condições dos tabuleiros costeiros do litoral norte da Paraíba, onde foi conduzido este experimento, por ser freqüente a ocorrência de solos com baixos teores de zinco. A ênfase para Zn se deve, também, à sua importância como micronutriente, envolvido em reações de redox e transporte de elétrons, de reações enzimáticas e da biossíntese do ácido 3-indol-acético (Taiz \& Zeiger, 2004). Este nutriente tem sido pouco estudado em cana-de-açúcar, encontrando-se apenas um trabalho, na literatura disponível, tratando da aplicação do micronutriente na cultura; realizado por Anderson \& Bowen (1992), foram observados efeitos positivos da aplicação de 7 $\mathrm{kg} \mathrm{ha}^{-1}$ de $\mathrm{Zn}$, na forma de sulfato de zinco, inclusive com efeitos residuais sobre os ciclos seguintes da cultura.

Grande parte dos trabalhos encontrados na literatura versa sobre concentração e conteúdo do micronutriente, como exemplo, o realizado por Orlando Filho et al. (1980) que verificaram exportação de 4,76 g de Zn por tonelada de colmos da cv. CB 41-76, na fase de planta, decrescendo para 3,49 $\mathrm{g} \mathrm{t}^{-1}$ na fase de soca. Na cv. Co 419, Orlando Filho (1993) observou exportação de 3,7 $\mathrm{g}$ de $\mathrm{Zn}$ por tonelada de colmos

Relacionado à fertilidade do solo, Carrijo et al. (2004) citam que, para os nutrientes com forte interação com a matriz do solo e que, predominantemente, se movimentam por difusão, como é o caso do zinco, o aumento da umidade do solo, com a utilização de irrigação, resulta em incremento na eficiência da adubação, especialmente, em solos arenosos. Segundo os autores, isso ocorre quando o fertilizante se concentra na região de maior umidade e maior concentração das raízes; a umidade favorece uma maior disponibilidade do nutriente para a planta e melhora sua movimentação no solo.

Objetivou-se com este trabalho, estudar a qualidade industrial da matéria-prima da cana-de-açúcar, quando cultivada em Tabuleiro Costeiro paraibano e submetida a diferentes lâminas de irrigação e níveis de adubação com zinco.

\section{MATERIAL E MÉTODOS}

Conduziu-se o experimento no período de setembro de 2004 a setembro de 2005, na Fazenda Capim II (latitude $6^{\circ}$ 54' $59,88^{\prime \prime} \mathrm{S}$, longitude $35^{\circ} 09^{\prime} 17,86$ " O e altitude de $121 \mathrm{~m}$ ), localizada no município de Capim, PB. Foi utilizada a cultivar SP 79-1011 de cana-de-açúcar (Saccharum Officinarum L.), classificada como precoce, com potencial para atingir uma produtividade média, na região do litoral norte paraibano, de 69,00 $\mathrm{t} \mathrm{ha}^{-1}$. É uma cultivar recomendada para áreas com solos de baixa a média fertilidade, prevendo-se o período de colheita 
para os meses de setembro a novembro (Nunes Jr. et al., 2003). Dentre suas principais características industriais, destacamse o teor de fibra $(14,7 \%)$, Pol da cana corrigida (PCC) de $10,5 \%$, pureza $79,74 \%$ e sólidos solúveis totais ( $\left.{ }^{\circ} \mathrm{Brix}\right)$ da ordem de 16,10\% (RIDESA, 2003).

Cinco lâminas de irrigação foram estudadas, em termos de fração da ETc (sequeiro, 25, 50, 75 e $100 \%$ da ETc.) e cinco níveis de adubação com zinco $\left(0,1,2,3\right.$ e $4 \mathrm{~kg} \mathrm{ha}^{-1}$ de $\left.\mathrm{Zn}\right)$, tendo como fonte o sulfato de zinco heptaidratado $\left(\mathrm{ZnSO}_{4} \cdot 7 \mathrm{H}_{2} \mathrm{O}\right)$, com $22 \%$ do nutriente; as quantidades do produto aplicadas nos tratamentos foram 0, 4,54, 9,08, 13,63 e 18,18 $\mathrm{kg} \mathrm{ha}^{-1}$.

O trabalho foi conduzido no delineamento experimental de blocos casualizados, em esquema fatorial 5 x 5 , com três repetições. A área foi subdividida em cinco setores de irrigação, cada um com cinco parcelas de adubação com zinco; o experimento contou com uma área vizinha, fora do raio de alcance da irrigação pelo pivô, para implantação do tratamento de sequeiro (sem irrigação), conforme ilustrado na Figura 1.
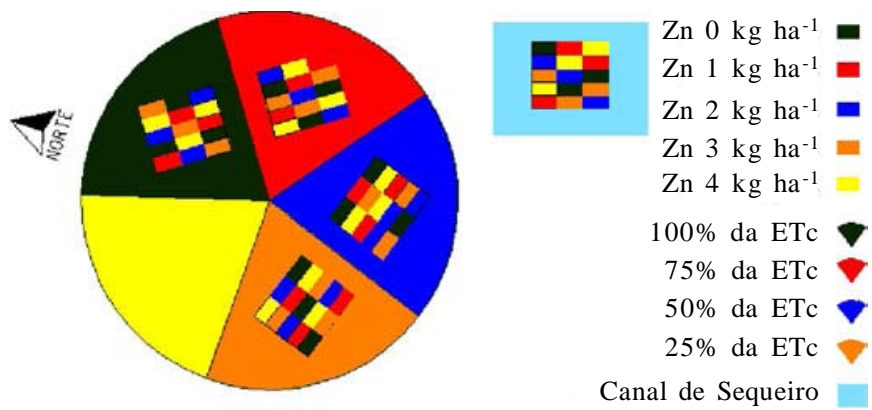

Figura 1. Área de co bertura do pivô central e distribuição dos setores, contendo os tratamentos

O solo da área experimental é classificado como Argissolo Vermelho Amarelo distrófico, de acordo com a classificação proposta por EMBRAPA (1999). O clima é quente e úmido, classificado como As', segundo Köppen, com chuvas de outono a inverno, temperatura e precipitação média anual de $28{ }^{\circ} \mathrm{C}$ e $1200 \mathrm{~mm}$, respectivamente, ocorrendo seis meses secos. Nas Tabelas 1 e 2 estão as características físico-hídricas e químicas do solo, destacando-se o baixo teor de zinco e os dados da análise química da água de irrigação, classificada como de boa qualidade $\left(\mathrm{C}_{1}\right)$.

$\mathrm{O}$ experimento foi conduzido com irrigação via pivô central fixo. O comprimento do centro do pivô até a última torre é de $257,4 \mathrm{~m}$, raio irrigado de $290 \mathrm{~m}$ e velocidade máxima de $127 \mathrm{~m} \mathrm{~h}^{-1}$, com o percentímetro regulado em $100 \%$. O conjunto eletrobomba é formado por um motor $\mathrm{WEG}^{\circledR}$ de $55,162 \mathrm{~kW}$ e uma bomba $\mathrm{KSB}^{\circledR}$ com vazão de $0,048 \mathrm{~m}^{3} \mathrm{~s}^{-1}$.

As irrigações, em caráter complementar, foram realizadas em turno de rega de nove dias. Na Figura 2 estão representados, graficamente, as lâminas aplicadas em função da ETc (mm $\operatorname{dia}^{-1}$ ) e os parâmetros climáticos, registrados na estação meteorológica localizada próximo à área experimental. Determinou-se, em um ensaio preliminar, a curva de controle do equipamento, aferindo-se a vazão do pivô com um hidrômetro instalado em sua entrada; determinou-se, também, o raio irri-
Tabela 1. Análise físico-hídrica e química do solo da área do experimento com a cultura da cana-de-açúcar

\begin{tabular}{|c|c|c|c|}
\hline \multirow{2}{*}{ Características do solo } & \multicolumn{3}{|c|}{ Profundidade $(\mathrm{cm})$} \\
\hline & $0-20$ & $21 \cdot 50$ & $51-100$ \\
\hline \multicolumn{4}{|c|}{ Granulometria (\%) } \\
\hline Areia & 73,0 & 68,86 & 55,64 \\
\hline Silte & 3,75 & 3,77 & 9,86 \\
\hline Argila & 23,25 & 27,37 & 33,50 \\
\hline Textura & FAA & FAA & FAA \\
\hline \multicolumn{4}{|c|}{ Densidade $\left(\mathrm{kg} \mathrm{dm}^{-3}\right)$} \\
\hline Aparente & 1,40 & 1,40 & 1,33 \\
\hline Real & 2,71 & 2,67 & 2,66 \\
\hline Porosidade (\%) & 48,33 & 47,56 & 50,00 \\
\hline \multicolumn{4}{|c|}{ Umidade natural } \\
\hline \multicolumn{4}{|l|}{ Umidade (\%) } \\
\hline $0,33(\mathrm{kPa})$ & 6,37 & 9,37 & 14,84 \\
\hline $15,00(\mathrm{kPa})$ & 3,88 & 5,69 & 9,11 \\
\hline Água disponível & 2,49 & 3,68 & 5,73 \\
\hline \multicolumn{4}{|c|}{ Complexo sortivo $\left(\mathrm{cmol}_{\mathrm{c}} \mathrm{dm}^{-3}\right)$} \\
\hline Cálcio & 1,97 & 1,45 & 1,51 \\
\hline Magnésio & 2,46 & 3,19 & 3,85 \\
\hline Sódio & 0,01 & 0,01 & 0,01 \\
\hline Potássio & 0,01 & 0,02 & 0,005 \\
\hline Soma de bases & 4,45 & 4,67 & 3,87 \\
\hline Hidrogênio & 0,79 & 0,92 & 0,26 \\
\hline Alumínio & 0,20 & 0,40 & 0,40 \\
\hline СТC & 5,44 & 5,99 & 6,03 \\
\hline Carbono orgânico (\%) & 0,40 & 0,41 & 0,38 \\
\hline Matéria orgânica (\%) & 0,69 & 0,71 & 0,65 \\
\hline Nitrogênio (\%) & 0,04 & 0,04 & 0,03 \\
\hline Fósforo (mg 100g-1) & 1,14 & 0,75 & 0,08 \\
\hline $\mathrm{pH}(\mathrm{H} 2 \mathrm{O})$ & 6,80 & 5,36 & 4,71 \\
\hline $\mathrm{CE}\left(\mathrm{dS} \mathrm{m}^{-1}\right)$ & 0,13 & 0,10 & 0,08 \\
\hline Znco (mg kg-1) & 0,90 & 0,80 & 0,5 \\
\hline Cobre $\left(\mathrm{mg} \mathrm{kg}^{-1}\right)$ & 1,40 & 1,20 & 1,00 \\
\hline Ferro $\left(\mathrm{mg} \mathrm{kg}^{-1}\right)$ & 120,00 & 140,00 & 155,00 \\
\hline Manganês (mg kg-1) & 2,50 & 1,50 & 0,90 \\
\hline
\end{tabular}

Tabela 2. Análise química da água utilizada na irrigação da área experimental

\begin{tabular}{lc}
\hline Características & Valor \\
pH & 6,20 \\
Condutividade elétrica $\left(\mathrm{S} \mathrm{cm}^{-1}\right)$ & 110 \\
Cálcio $\left(\mathrm{mmol}_{\mathrm{c}} \mathrm{L}^{-1}\right)$ & 0,22 \\
Magnésio $\left(\mathrm{mmol}_{\mathrm{c}} \mathrm{L}^{-1}\right)$ & 0,43 \\
Sódio $\left(\mathrm{mmol}_{\mathrm{c}} \mathrm{L}^{-1}\right)$ & 0,55 \\
Potássio $\left(\mathrm{mmol}_{\mathrm{c}} \mathrm{L}^{-1}\right)$ & 0,07 \\
Cloretos $\left(\mathrm{mmol}_{\mathrm{c}} \mathrm{L}^{-1}\right)$ & 0,65 \\
Sulfatos $\left(\mathrm{mmol}_{\mathrm{c}} \mathrm{L}^{-1}\right)$ & Ausência \\
Bicarbonatos $\left(\mathrm{mmol}_{\mathrm{c}} \mathrm{L}^{-1}\right)$ & 0,23 \\
Carbonatos $\left(\mathrm{mmol}_{\mathrm{c}} \mathrm{L}^{-1}\right)$ & 0,00 \\
Relação de adsorção de sódio - RAS (mmol L-1) & 0,96 \\
Classe de água & $\mathrm{C}_{1}$ \\
\hline
\end{tabular}

gado (m), contando com o canhão hidráulico no lance final; com tais procedimentos, calculou-se o tempo de giro $(\mathrm{Tg})$, com o relé percentímetro regulado em 100\%, segundo a Eq. 1:

$$
\operatorname{Tg}=\frac{2 * \pi * \mathrm{r}}{\mathrm{V}}
$$


em que:

$\mathrm{r}$ - raio do pivô até a última torre, $\mathrm{m}$

$\mathrm{V}$ - velocidade do pivô (última torre), $\mathrm{m} \mathrm{h}^{-1}$

A determinação da lâmina bruta (Lb) aplicada pelo equipamento, quando regulado em $100 \%$, foi estimada conforme a equação, a seguir:

$$
\mathrm{Lb}=\frac{\mathrm{Q} * \mathrm{Tg}}{10 * \mathrm{~A}}
$$

em que:

$$
\begin{aligned}
& \text { Q - vazão, } \mathrm{m}^{3} \mathrm{~s}^{-1} \\
& \text { A - área irrigada, ha }
\end{aligned}
$$

Para uniformização das condições hídricas do solo na área experimental, a primeira irrigação foi feita elevando-se o teor de umidade do solo ao nível da capacidade de campo; a partir daí, iniciou-se a aplicação dos tratamentos de irrigação. Considerando-se a falta de informações sobre interceptação de água na cultura de cana-de-açúcar, neste experimento foram utilizados os resultados de Silva et al. (1994); esses autores, trabalhando com milho, observaram serem interceptados, pelas folhas das plantas, $26 \%$ da precipitação total, ou seja, é de $74 \%$ a chuva efetiva para essa cultura, nas condições do planalto central do Brasil.

O manejo de irrigação se deu com base no tanque "classe $\mathrm{A}$ ", utilizando-se da equação ETc $=\mathrm{ETo} * \mathrm{kc}$ e dos valores de kc para a cultura de cana, citados por Doorenbos \& Kassam (1979), correspondentes aos diferentes estádios de desenvolvimento.

No balanço hídrico foi computado como chuva efetiva, para as condições de sequeiro, o total de $74 \%$ da precipitação; entretanto, para os demais tratamentos foi calculado o consumo diário, considerando-se a água armazenada no solo e a precipitação pluviométrica diária; assim, a diferença entre o consumo e o que choveu correspondeu à lâmina de irrigação para o tratamento de $100 \%$ da ETc, sendo, para os demais tratamentos, corrigida a lâmina para as frações de 25,50 e $75 \%$ da ETc.

Na Tabela 3 estão expostas as lâminas de irrigação aplicadas, ao longo do ano de cultivo, e as respectivas precipitações efetivas; as precipitações totalizaram $1100 \mathrm{~mm}$, sendo bastante aproximados os totais de água aplicados nos tratamentos que receberam $25,50,75$ e $100 \%$ da ETc, devido provavelmente, ao fato de as chuvas terem-se concentrado em apenas três meses; nota-se, pelos dados contidos na Figura 2C, que o período de cultivo foi marcado por um ciclo muito longo de estiagem e uma estação chu-

Tabela 3. Lâmina de água de irrigação, precipitação efetiva, lâmina total aplicada à cultura e precipitação total no ano de cultivo

\begin{tabular}{lcccc}
\hline $\begin{array}{c}\text { Tratamento de } \\
\text { imigação }\end{array}$ & $\begin{array}{c}\text { Lâmina } \\
\text { aplicada (mm) }\end{array}$ & $\begin{array}{c}\text { Precipitação } \\
\text { efetiva }(\mathbf{m m})\end{array}$ & Lâmina total & $\begin{array}{c}\text { Precipitação } \\
\text { total (mm) }\end{array}$ \\
Sequeiro & 0 & 780,06 & 780,06 & \\
$25 \%$ da ETc & 256,64 & 731,31 & 987,95 & \\
$50 \%$ da ETc & 513,29 & 487,54 & $1.000,83$ & 1.100 \\
$75 \%$ da ETc & 769,93 & 243,77 & $1.013,70$ & \\
$100 \%$ da ETc & $1.026,57$ & 194,51 & $1.221,08$ & \\
\hline
\end{tabular}
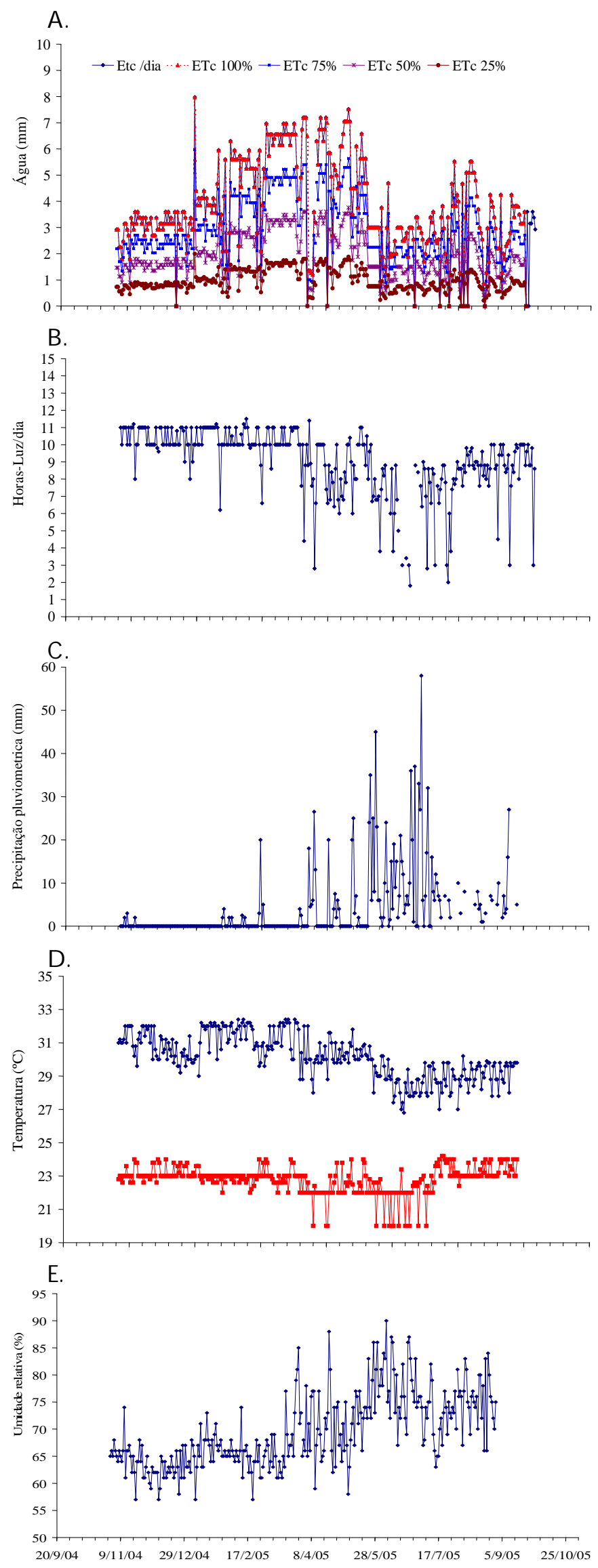

Figura 2. (A) Lâmina de água de irrigação, (B) hora de luz por dia, (C) pluviometria (mm), (D) temperatura máxima e mínima, (E) umidade relativa do ar (\%) durante o período experimental 
vosa muito irregular e concentrada, com veranicos frequentes.

Os efeitos dos tratamentos foram avaliados em relação a ${ }^{\circ}$ Brix, sacarose (Pol), Pol da cana corrigido (PCC), fibra industrial (FIB), pureza (PUR) e açúcares totais recuperáveis (ATR). A determinação do ${ }^{\circ}$ Brix do caldo extraído foi efetuada com refratômetro digital provido de correção automática de temperatura para $20^{\circ} \mathrm{C}$ (Caldas, 1998).

A Pol foi avaliada com um sacarímetro automático ACATEC, modelo DAS 2500, determinando-se a concentração de açúcares opticamente ativos, com base na equação conhecida como lei de Biot (Caldas, 1998), apresentada na Eq. 3.

$$
\mathrm{C}=\frac{100 * \alpha}{1 * \alpha^{\mathrm{T}} * \lambda}
$$

em que:

C - Concentração de açúcares

$\alpha$ - Ângulo de rotação do plano de vibração da luz polarizada

1 - Comprimento da coluna iluminada de líquido

$\alpha^{T} \cdot \lambda$ - Rotação específica

Após a leitura realizada pelo aparelho, é feita a correção para temperatura ambiente interna, em torno de $20^{\circ} \mathrm{C}$, pela Eq. 4 de ajuste.

$$
\mathrm{L}_{\text {corrigida }}=\mathrm{L} *[1+0,000255 *(\mathrm{~T}-20)]
$$

em que:

$$
\begin{gathered}
\text { L - Leitura sem correção } \\
\text { T - Temperatura do laboratório } \\
\mathrm{L}_{\text {corrigida }} \text { - Pol do caldo extraído (\%) }
\end{gathered}
$$

O cálculo da fibra industrial (FIB \%) da cana se baseia na correlação entre resíduo fibroso e a fibra industrial da cana, determinada experimentalmente, segundo a seguinte equação (CRSPCTS/PB, 1997):

$$
\mathrm{FIB} \%_{\text {cana }}=\frac{(100 * \mathrm{PBS}) *(\mathrm{PBU} * \mathrm{~b})}{5 *(100-\mathrm{b})}
$$

em que:

PBS - Peso do bolo seco em estufa à $105^{\circ} \mathrm{C}$

PBU - Peso do bolo úmido: resíduo fibroso, resultante da prensagem a $250 \mathrm{kgf} \mathrm{cm}^{-2}$ por $1 \mathrm{~min}$, de $500 \mathrm{~g}$ de amostra de cana desfibrada e homogeneizada, em grama (CONSECANA, 2001)

b - ${ }^{\circ}$ Brix do caldo extraído

Obteve-se a pureza (PUR) a partir da percentagem de sólidos solúveis totais no caldo extraído, após a determi-

$$
\mathrm{PUR}=\frac{\mathrm{Pol}_{\text {caldo }}}{\mathrm{Brix} \%_{\text {caldo }}} * 100
$$

nação dos valores de Pol e ${ }^{\circ}$ Brix (CRSPCTS/PB, 1997), segundo a Eq.6.

O PCC é um índice que determina o valor da tonelada de cana; valor alto de PCC significa preço elevado da cana, sen- do, portanto um fator de ágio ou deságio. A sua determinação se dá através da Eq.7.

$$
\mathrm{PCC}=\mathrm{L}_{\text {corrigida }} *(1-0,01 * \mathrm{FIB}) * \mathrm{c}
$$

em que:

$$
\begin{aligned}
& \mathrm{L}_{\text {corrigida }} \text { - Pol do caldo extraído, } \% \\
& \text { FIB = } \text { Fibra industrial da cana, } \% \\
& \mathrm{c}= 0,955, \text { fator de transformação da Pol do caldo } \\
& \text { extraído em Pol do caldo absoluto }
\end{aligned}
$$

Os dados coletados neste trabalho foram analisados, seguindo-se recomendações de Gomes (2000) e Santos et al. (2002), segundo os quais, em experimentos dessa natureza, o esquema de análise mais apropriado é a análise conjunta de experimentos, sendo necessário se verificar a homogeneidade dos quadrados médios dos resíduos; caso a relação entre o maior $\mathrm{QM}_{\text {resíduo }}$ e o menor $\mathrm{QM}_{\text {resíduo }}$ seja menor que 7, podese adotar a análise conjunta de experimentos.

Para a análise conjunta, consideraram-se os setores de irrigação como geograficamente diferentes, em que foram testados os níveis de zinco, com base em Ribeiro Jr. (2001), de acordo com os seguintes procedimentos para utilização do software SAEG 9.0: as parcelas foram formadas por nove fileiras de cana-de-açúcar (espaçamento de 1,20 m), com $12 \mathrm{~m}$ de comprimento (9 linhas x $12 \mathrm{~m}$ ), totalizando $108 \mathrm{~m}\left(129,6 \mathrm{~m}^{2}\right)$; a área útil para a coleta dos dados, tanto para as amostras mensais como para a amostragem final, foi composta de 7 fileiras centrais de $10 \mathrm{~m}$, totalizando $84,0 \mathrm{~m}^{2}$.

\section{RESULTADOS E DISCUSSÃO}

Na Tabela 4 constam os resultados do estudo da correlação de Pearson, verificando-se significativa correlação positiva entre as lâminas de irrigação e a maioria dos índices tecnológicos; nos casos em que foi negativa a correlação (FIB e PBU), tal comportamento é favorável à qualidade da matéria prima; portanto, a quantidade de água aplicada na irrigação teve papel fundamental na qualidade da cana-de-açúcar, haja vista a alta significância ( $p<0,01)$, entre esse fator e as variáveis tecnológicas.

Ao contrário, não se registrou qualquer correlação significativa entre $\mathrm{Zn}$ e as variáveis avaliadas, uma evidência de não haver influência deste micronutriente sobre os índices tecnológicos da cultivar de cana SP 79-1011, cultivada em condições de Tabuleiros Costeiros de Mamanguape, PB, mesmo sendo o solo deficiente no nutriente (Tabela 1).

Como complemento à interpretação dos dados de correlação, apresentam-se, na Tabela 5, o resumo da análise de variância e, na Figura 3, a representação gráfica dos estudos de regressão, podendo-se avaliar melhor os efeitos dos tratamentos de irrigação sobre cada variável. Em termos de sólidos solúveis totais, expressos em ${ }^{\circ}$ Brix, foi significativa a regressão linear entre lâminas de água e esta variável que variou de forma crescente, com o aumento da quantidade de água; pela equação obtida, há um aumento de $0,72{ }^{\circ}$ Brix por incremento de $100 \mathrm{~mm}$ na lâmina de irrigação aplicada (Figura 3A); nas condições da pesquisa, o teor mínimo de ${ }^{\circ}$ Brix é de 12,035. 
Tabela 4. Estudos de correlação de Pearson dos fatores lâminas e zinco com as variáveis tecnológicas da cana-de-açúcar

\begin{tabular}{lcccc}
\hline \multicolumn{1}{c}{ Variável* } & Variável & Correlação & T & Significância \\
PUR & FIB & $-0,3408$ & $-3,0973$ & 0,0010 \\
PUR & ATR & 0,9337 & 22,2840 & 0,0001 \\
FIB & ATR & $-0,4814$ & $-4,6921$ & 0,0001 \\
Lâmina & SST & 0,8122 & 11,8956 & 0,0001 \\
Lâmina & POL & 0,8448 & 13,4903 & 0,0001 \\
Lâmina & PUR & 0,8237 & 12,4130 & 0,0001 \\
Lâmina & FIB & $-0,5097$ & $-5,0616$ & 0,0001 \\
Lâmina & PCC & 0,8704 & 15,1055 & 0,0001 \\
Lâmina & PC & 0,8764 & 15,5463 & 0,0001 \\
Lâmina & PBU & $-0,4805$ & $-4,6815$ & 0,0001 \\
Lâmina & ATR & 0,8584 & 14,2969 & 0,0001 \\
Zn & SST & 0,0458 & 0,3917 & 0,3476 \\
Zn & POL & 0,0634 & 0,5431 & 0,2935 \\
Zn & PUR & 0,0068 & 0,0580 & 0,4769 \\
Zn & FIB & $-0,1857$ & $-1,6144$ & 0,0532 \\
Zn & PCC & 0,0722 & 0,6182 & 0,2682 \\
Zn & PC & 0,0802 & 0,6875 & 0,2459 \\
Zn & PBU & $-0,1930$ & $-1,6807$ & 0,0464 \\
Zn & ATR & 0,0887 & 0,7611 & 0,2233 \\
\hline
\end{tabular}

*PUR - pureza; FIB - fibra; ATR - açúcares totais recuperáveis; SST sólidos solúveis totais; POL - polarização (sacarose); PCC - pol da cana corrigida; PBU - peso do bolo úmido; $\mathrm{T}$ - teste $\mathrm{T}$
Utilizando-se dos dados de brix registrados nos tratamentos de sequeiro, em que a precipitação efetiva foi de 780,06 $\mathrm{mm}$ ( ${ }^{\circ}$ Brix $\left.=17,65 \%\right)$ e de $100 \%$ da ETc, com lâmina total aplicada de 1.221,08 mm ( ${ }^{\circ}$ Brix $=20,83 \%$ ), ocorreu um acréscimo de $18,02 \%$ nos sólidos solúveis totais.

Como aconteceu com os sólidos solúveis totais, a Pol da cana-de-açúcar cresceu em função das lâminas da água de irrigação, com forte correlação positiva $\left(r_{p}=0,8448\right)$ (Tabela 4) e, nos estudos de regressão, verificou-se efeito linear e crescente entre Pol e os tratamentos de irrigação. Segundo a equação de regressão (Figura 3B), a Pol aumenta $0,99 \%$ por cada incremento de $100 \mathrm{~mm}$ na quantidade de água aplicada na irrigação da cana, a partir de 6,9127, valor mínimo registrado nesta variável. Com base na equação, analisando-se os valores de Pol obtidos nos tratamentos de sequeiro $(14,64 \%)$ e de $100 \%$ da ETc $(19,00 \%)$, ocorreu acréscimo de $29,28 \%$, um aumento considerável.

Notam-se serem valores aproximados os de Pol e de PCC (Pol da cana corrigida), sendo esta variável derivada daquela, por correção da leitura, assumindo-se a Pol como PCC, pois um ponto de diferença representa um ganho real para a indústria (Caldas, 1998; Caputo et al., 2007). Foi, igualmente, significativa $(\mathrm{p}<0,01)$ a correlação entre PCC e os tratamentos de irrigação (Tabela 4). Com base na equação de regres-

Tabela 5. Resumo da análise de variância para os índices tecnológicos da cana-de-açúcar (variedade SP 79 1011), no primeiro ano do experimento

\begin{tabular}{|c|c|c|c|c|c|c|c|}
\hline \multirow{2}{*}{ Fonte de variação } & \multicolumn{7}{|c|}{ ANOVA/Índices tecnológicos da cana-de-açúcar } \\
\hline & SST & POL & PUR & FIB & PBU & PCC & ATR \\
\hline & \multicolumn{7}{|c|}{ Quadrados médios } \\
\hline Bloco/lâm. & $0,3306 \mathrm{~ns}$ & $0,3011 \mathrm{~ns}$ & 2,2069 ns & $0,2821 \mathrm{~ns}$ & $18,8762 \mathrm{~ns}$ & $0,2630 \mathrm{~ns}$ & $22,4426 n s$ \\
\hline Lâmina & $24,2310 * *$ & $43,9960 * *$ & $164,16^{* *}$ & $4,1023^{* *}$ & $360,5232 * *$ & $31,6989 * *$ & $2692,208^{* *}$ \\
\hline $\mathrm{Zn}$ & $0,2006 \mathrm{~ns}$ & $0,8303 \mathrm{~ns}$ & $1,2704 \mathrm{~ns}$ & $0,5882 \mathrm{~ns}$ & $51,2568 \mathrm{~ns}$ & $0,3952 \mathrm{~ns}$ & $58,1339 n$ \\
\hline Lâm. x Zn & 0,8341 ns & $0,8563 \mathrm{~ns}$ & $2,7462 \mathrm{~ns}$ & $0,2455 \mathrm{~ns}$ & $39,5197 \mathrm{~ns}$ & $0,5336 \mathrm{~ns}$ & $45,1272 n s$ \\
\hline QMR & 0,3951 & 0,6154 & 2,6473 & 0,5578 & 0,3294 & 51,8306 & 33,2443 \\
\hline \multirow[t]{2}{*}{ CV (\%) } & 3,27 & 4,66 & 1,86 & 5,05 & 4,24 & 4,95 & 4,34 \\
\hline & \multicolumn{7}{|c|}{ ANOVA e índices de regressão } \\
\hline Modelo & Linear & Linear & Linear & Quadrático & Quadrático & Linear & Quadrático \\
\hline Sig. a & 0,0243 & 0,0183 & 0,0134 & 0,0378 & 0,01132 & 0,0105 & 0,0138 \\
\hline Sig. b & & & & 0,0273 & 0,0090 & & 0,2001 \\
\hline QMDR & 5,0138 & 9,5178 & 38,3346 & 0,5359 & 47,7942 & 7,3618 & 333,70 \\
\hline $\mathrm{F}$ & 10,36 & 12,99 & 16,56 & 38,65 & 145,38 & 19,88 & 13,22 \\
\hline \multirow[t]{3}{*}{ Prob. F } & 0,0486 & 0,0366 & 0,0268 & 0,0252 & 0,0068 & 0,0210 & 0,0403 \\
\hline & \multicolumn{7}{|c|}{ Médias para lâmina de água de irrigação } \\
\hline & $\left({ }^{\circ}\right.$ Brix) & $(\%)$ & $(\%)$ & $(\%)$ & (g) & $(\%)$ & $(\mathrm{kg} \mathrm{t}-1)$ \\
\hline Sequeiro & 17,98 & 14,16 & 81,83 & 15,01 & 149,28 & 12,34 & 112,27 \\
\hline $25 \%$ ETC & 18,57 & 16,05 & 86,36 & 14,97 & 147,56 & 12,84 & 127,92 \\
\hline $50 \% \mathrm{ETC}$ & 19,86 & 17,59 & 88,99 & 14,80 & 147,32 & 14,16 & 138,03 \\
\hline $75 \%$ ETC & 19,96 & 17,75 & 88,56 & 14,66 & 145,90 & 14,12 & 138,28 \\
\hline \multirow[t]{2}{*}{$100 \%$ ETC } & 20,37 & 18,45 & 90,47 & 13,73 & 136,88 & 15,11 & 147,47 \\
\hline & \multicolumn{7}{|c|}{ Médias para níveis de zinco } \\
\hline 0 & 19,07 & 16,60 & 86,86 & 14,88 & 148,21 & 13,35 & 139,30 \\
\hline 1 & 19,17 & 16,97 & 87,18 & 14,63 & 145,49 & 13,39 & 145,49 \\
\hline 2 & 19,27 & 16,90 & 87,46 & 14,80 & 145,80 & 13,61 & 145,80 \\
\hline 3 & 19,38 & 17,17 & 87,40 & 14,43 & 143,62 & 13,75 & 143,62 \\
\hline 4 & 19,18 & 16,72 & 86,84 & 14,45 & 143,83 & 13,54 & 143,83 \\
\hline
\end{tabular}

${ }^{1}$ SST - Sólidos solúveis totais; POL - Leitura polarimétrica; PUR - Pureza; FIB - Teor de fibra; PBU - Peso do bolo úmido; PCC - Pol da cana corrigida; ATR - Açúcares totais recuperáveis; QMR - quadrado médio do resíduo; QMDR - quadrado médio devido a regressão; CV(\%) - Coeficiente de variação; Prob.F - Significância do Teste F (valores entre zero e 0,01 são significativos a 1\%; valores entre 0,01 e 0,05 são significativos a $5 \%$ ); *- significativo a $1 \%$; **- significativo a $5 \%$ 
A.

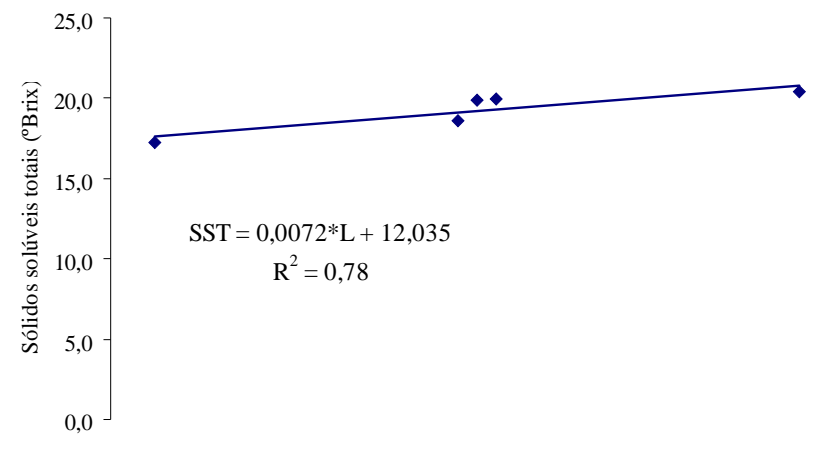

B.

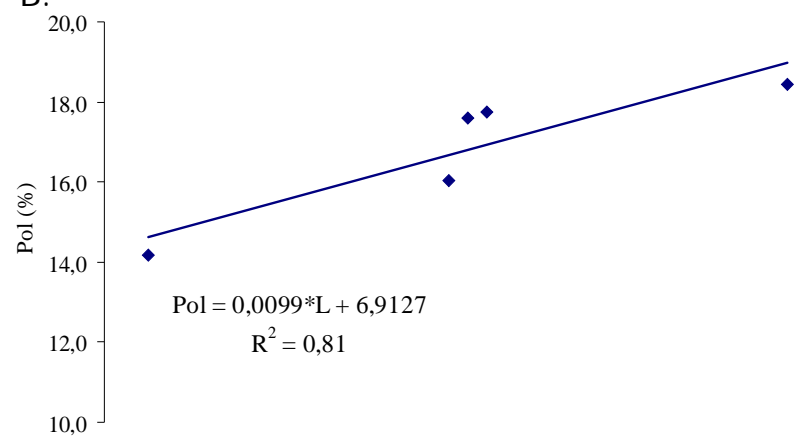

C.

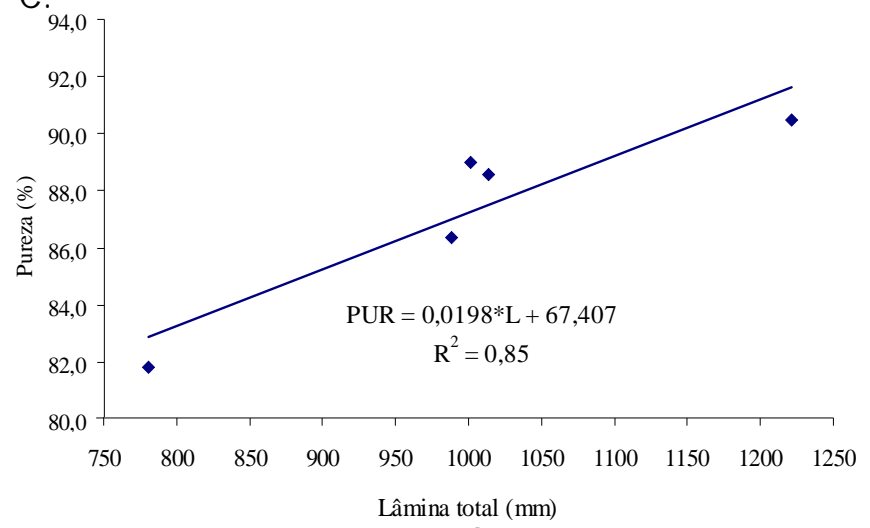

G.
D.

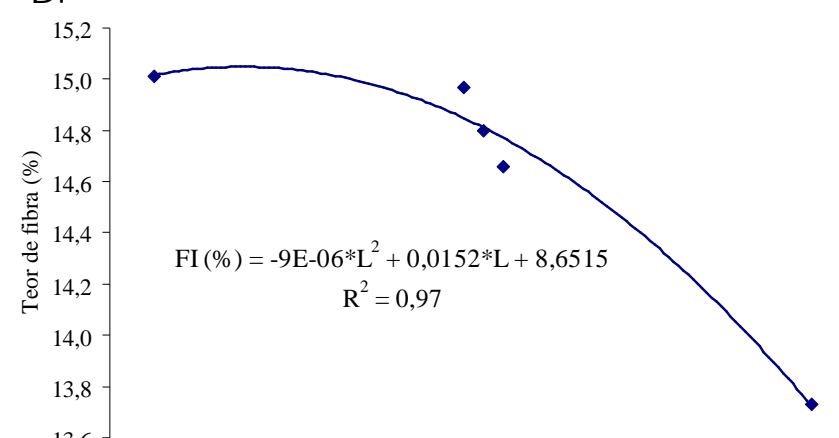

E.

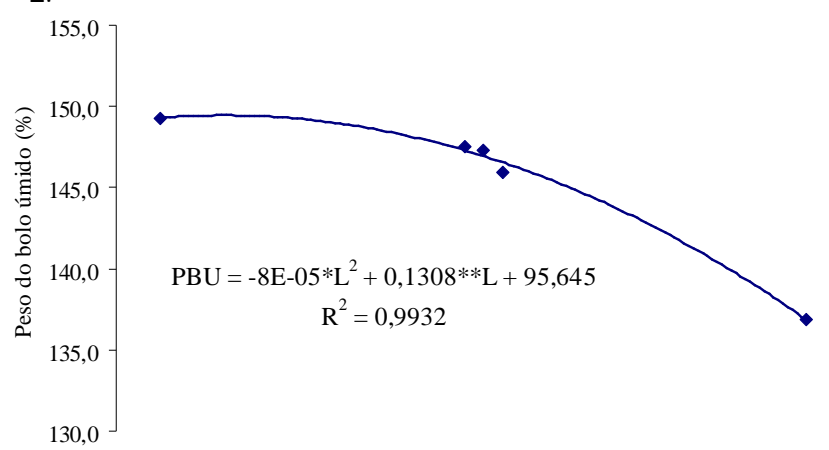

F.

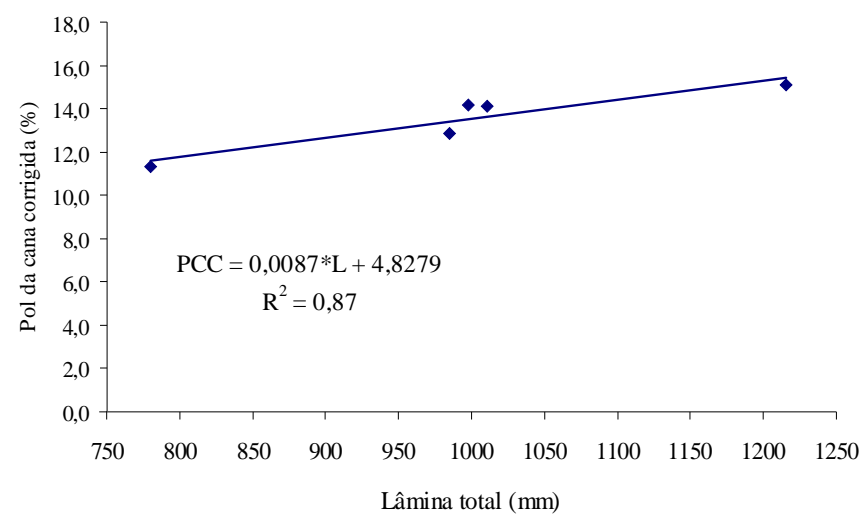

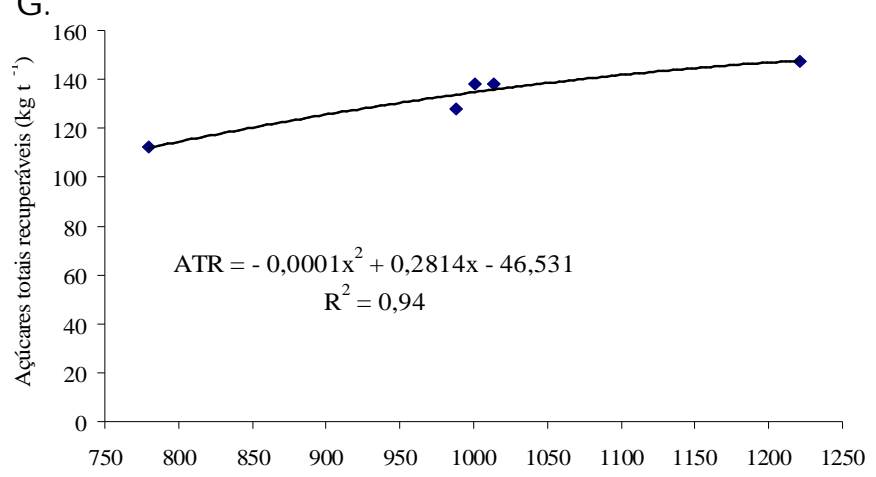

Lâmina total (mm)

Figura 3. Estudo de regressão para os índices tecnológicos da cana: (A) sólidos solúveis totais, em örix; (B) pol, \%; (C) pureza, \%; (D) teor de fibra, \%; (E) PBU; (F) PCC \%; (G) Açucares totais recuperáveis ATR, $\mathrm{kg} \mathrm{t}^{-1}$, em função da lâmina total de água aplicada

são, contida na Figura 3F, o aumento de PCC, por incremento de $100 \mathrm{~mm}$ nas lâminas de irrigação, foi de $0,87 \%$, um pouco menor que o registrado para Pol, como discutido anteriormente. A diferença entre os dados de PCC da cana submetida ao regime de sequeiro e a que recebeu $100 \%$ da ETc (Tabela 5), foi de 33,07\%, com base na equação de regressão. Robertson et al. (1999) verificaram queda no rendimento em sacarose, reduzindo de 2,79 para $0,91 \mathrm{tha}^{-1}$ entre os tratamentos de irrigação plena e de déficit hídrico. Para Wiedenfeld (2000), a redução nos índices de sacarose depende do estádio de desenvolvimento em que ocorrer estresse hídrico; o autor estudou os efeitos de déficit hídrico em cinco diferentes estádios 
de desenvolvimento das plantas, registrando reduções de 11 a $19 \%$ na PCC, dependendo do estádio fenológico da cultura.

Em relação à PUR (pureza), os resultados obtidos estão em concordância com os encontrados na literatura (Caldas, 1998; Bovi \& Serra, 1999; Leite, 2005), correlacionando-se positivamente, em alto grau (Tabela 4), com a ATR $\left(r_{p}=0,9337\right)$; com o teor de fibras (FIB), a correlação foi baixa $\left(r_{p}=-0,3408\right)$ e negativa, uma indicação de baixar a pureza com o aumento de FIB. Estas observações estão em acordo com os procedimentos do Sistema de Pagamento de Cana pelo Teor de Sacarose (SPCTS), prática comum nas Usinas de cana-de-açúcar, segundo os quais, a pureza se relaciona, inversamente com o teor de fibras (Valsechi, 1983).

A pureza (PUR) foi influenciada, também, pelas lâminas de água testadas na irrigação das plantas ( $\mathrm{p}<0,01)$; maior pureza (Tabela 5) foi obtida quando a cultura foi irrigada com $100 \%$ da ETc (90,47\%); quando se comparou a cana cultivada em regime de sequeiro, com a que recebeu o maior nível de irrigação, a pureza aumentou 10,56\%; em relação à cana irrigada com $100 \%$ da ETc, nas plantas cultivadas com 25,50 e $75 \%$ da ETc, a PUR decresceu 4,54, 1,64 e 2,11, respectivamente.

Quanto ao teor de fibras, observa-se, pelos dados da análise de variância, ter sido quadrático o modelo interpretativo dos efeitos das lâminas de irrigação sobre FIB (Tabela 5). Pela equação de regressão (Figura 3D), maior teor de fibras $(15,07)$ foi estimado para uma lâmina de $844,4 \mathrm{~mm}$, decrescendo à medida que aumentou a quantidade de água de irrigação; o menor teor de fibra $(13,79 \%)$ foi observado na cana submetida ao tratamento de $100 \%$ da ETc, uma queda de $8,25 \%$, em relação à cana de sequeiro, com base na equação de regressão.

O peso do bolo úmido (PBU), cujos dados estão na Tabela 5, é utilizado na determinação do cálculo do teor de fibra (Caldas, 1998, Bovi \& Serra, 1999); foi, influenciado também pela irrigação, com comportamento quadrático para as lâminas de água estudadas. Pelo estudo de correlação de Pearson (Tabela 4), há uma correlação moderadamente negativa $\left(r_{p}=-0,4805\right)$, entre essa variável e PBU, estatisticamente significativa; portanto, à medida que se aumentou a lâmina de irrigação, reduziu-se o peso do bolo úmido. Analisando-se o modelo quadrático, obtido por regressão, nota-se que o máximo de PBU $(149,11 \mathrm{~g})$ foi estimado para a lâmina de 817,50 $\mathrm{mm}$ de irrigação.

Em todo o Brasil, a cana-de-açúcar tem sido remunerada por seus índices qualitativos, de modo que, quanto melhor a qualidade da matéria prima, maior é o preço pago por tonelada de colmos. Todos os índices, discutidos neste trabalho, são usados como base de cálculo para se determinar a quantidade de açúcares totais recuperáveis, expressos em kg de ATR t ${ }^{-1}$ de cana. Pelos resultados desta pesquisa se comprova que a qualidade da matéria prima pode ser melhorada com a irrigação. Em termos de ATR (Tabela 5), a cana-de-açúcar foi influenciada pela lâmina de água de irrigação, com significância de $1 \%$ de probabilidade; os dados se ajustaram ao modelo quadrático de regressão (Figura 3G), com ATR sempre crescente nos níveis de irrigação estudados.
Com o cultivo de cana em regime de sequeiro, obteve-se uma produtividade agrícola equivalente a $3.494,96 \mathrm{~kg} \mathrm{ha}^{-1} \mathrm{de}$ açúcar, enquanto a irrigada com $25 \%$ da ETc produziu 6.720,90 $\mathrm{kg} \mathrm{ha}^{-1}$; ao ser cultivada com $50 \%$ da ETc, a produção média em açúcar foi de $9.978,18 \mathrm{~kg} \mathrm{ha}^{-1}$, passando para $10.007,32 \mathrm{~kg}$ ha $^{-1}$ quando a cultura foi irrigada com $75 \%$ da ETc. Um grande diferencial para a cana-de-açúcar irrigada com $100 \%$ da ETc foi a sua produtividade em açúcar, de $12.992,10 \mathrm{~kg} \mathrm{ha}^{-1}$, evidenciando o acréscimo em açúcar com a utilização da tecnologia de irrigação suplementar, via pivô central. O maior teor de ATR, em relação aos tratamentos estudados, se deu quando a cultura foi irrigada com $100 \%$ da ETc $\left(147,47 \mathrm{~kg} \mathrm{t}^{-1}\right)$. Observa-se que nos tratamentos que envolveram irrigação, a 50 e $75 \%$ da ETc, a produção de açúcar foi muito aproximada, com média de $138,16 \mathrm{~kg} \mathrm{t}^{-1}$, representando uma diferença de $9,31 \mathrm{~kg} \mathrm{t}^{-1}(6,31 \%)$ quando comparada com a cana irrigada com $100 \%$ da ETc. Segundo os valores da correlação de Pearson (Tabela 4), obteve-se forte correlação positiva $\left(r_{p}=0,8584\right)$ e significativa ( $\mathrm{p}<0,01)$, entre a lâmina de água de irrigação e a ATR; portanto, à medida que se aumenta a lâmina de água de irrigação cresce, também, o teor de ATR. Molinari et al. (2007) também se reportam ao aumento do teor de açúcares, com adequado suprimento hídrico às plantas; sob condições de estresse hídrico, esses autores verificaram aumento do teor de prolina, ao invés de açúcares.

Quando se comparou a cana que recebeu $100 \%$ da ETc $\left(147,47 \mathrm{~kg}\right.$ de ATR t $\left.{ }^{-1}\right)$ com a cana irrigada com $25 \%$ da ETc $\left(127,92 \mathrm{~kg}\right.$ de ATR $\left.\mathrm{t}^{-1}\right)$, a diferença foi de $19,55 \mathrm{~kg}$ de ATR $\mathrm{t}^{-1}$ de cana (13,26\% menor); a mesma comparação foi realizada quanto à cana de sequeiro $\left(112,27 \mathrm{~kg}\right.$ de ATR $\left.\mathrm{t}^{-1}\right)$, observando-se diferença de $35,20 \mathrm{~kg}^{\text {de ATR t}}{ }^{-1}$ de cana (queda de $23,87 \%$ ). Ressalta-se que a cana foi cortada no mês de setembro de 2005 (primeiro mês de moagem) e que, no período de 01/09/2005 a 30/09/2005, conforme gerente da usina (comunicação pessoal) a Destilaria Miriri moeu 103.088,490 t de canade-açúcar, sendo o teor médio de ATR do período, de 110,27 $\mathrm{kg}$. Analogamente, comparando-se o teor médio de ATR da cana irrigada com $100 \%$ da ETc com a média de ATR do mês de setembro, a diferença foi de $37,20 \mathrm{~kg} \mathrm{t}^{-1}$; da mesma forma, em relação à cana irrigada com 75, 50, 25\% da ETc e de sequeiro, as respectivas diferenças foram 9,19, 9,44 19,55 e 35,2 $\mathrm{kg} \mathrm{t}^{-1}$. De acordo com Burnquist (1999), o sistema CONSECANA elegeu a definição de Açúcares Totais Recuperáveis como base de cálculo para a constituição do valor da tonelada de cana. A Associação dos Plantadores de Cana-de-açúcar da Paraíba (ASPLAN) divulgou, em seu relatório anual, o preço médio da ATR para o mês de setembro de 2005, fixando-o em $R$ \$ 0,3177 $\mathrm{kg}^{-1}$ de ATR (valor líquido); tal fato repercute em uma diferença de $\mathrm{R} \$ 11,18$ no pagamento de uma tonelada de cana.

A melhoria na qualidade da matéria prima, observada neste trabalho, resultante da quantidade de água aplicada na irrigação, pode estar, em parte, relacionada ao maior Índice de Área Foliar (IAF) desenvolvido pelas plantas, como verificaram Farias et al. (2007), avaliando os efeitos das mesmas lâminas de irrigação na cana-de-açúcar. Pode-se inferir que a melhoria na qualidade da matéria prima se deu em virtude do aumento da área foliar efetiva das plantas; o IAF está intimamente associado à quantidade de luz absorvida e com a fo- 
tossíntese. Segundo Taiz \& Zeiger (2004), na fotossíntese os vegetais transformam energia solar em energia química, sendo a produtividade das culturas uma função direta da eficiência fotossintética.

\section{CONCLUSÕES}

1. Há forte correlação entre a lâmina de água de irrigação e as variáveis que definem a qualidade da matéria prima da cana-de-açúcar.

2. Em termos de ATR (açúcares totais recuperáveis), a cana irrigada com $100 \%$ da ETc produziu $6,74 \%$ a mais que a média das plantas irrigadas com 75 e $50 \%$ da ETc; e produziu $15,28 \%$ a mais que a cana irrigada com $25 \%$ da ETc; é de $31,35 \%$ a diferença entre a cana irrigada com a maior lâmina e a cultivada sob regime de sequeiro.

3. Não há efeito das doses de Zn sobre os índices industriais da cana-de-açúcar.

\section{AGRADECIMENTO}

À Destilaria Miriri S.A e União Agrícola Ltda, por todo o apoio e incentivo à pesquisa; ao Dr. Gilvan Celso Cavalcanti de Morais Sobrinho, seu Diretor Superintendente, um líder visionário à frente de seu tempo.

\section{LITERATURA CITADA}

Alfonsi, R. R.; Pedro Júnior, M. J.; Brunini, O.; Barbieri, V. Condições climáticas para a cana-de-açúcar: Cana-de-açúcar: cultivo e utilização. In: Paranhos, S.B. (Coord). Campinas: Fundação Cargill, v.1, 1987. p.42-55.

Anderson, D.L.; Bowen, J.E. Nutrição da cana-de-açúcar (tradução de José Orlando Filho). Piracicaba: Potafos. 1992, 40p.

Blackburn, F. Sugar-cane. New York: Longman, 1984. 414p.

Bovi, R.; Serra, G. E. Impurezas fibrosas da cana-de-açúcar e parâmetros tecnológicos do caldo extraído. Scientia Agricola, v.56, n.4, p.885-896, 1999.

Burnquist, H. L. Pagamento de cana: O sistema de remuneração da tonelada de cana pela qualidade - CONSECANA. Preços agrícolas, maio, p.14-16, 1999.

Caldas, C. Manual de análises selecionadas para indústrias sucroalcooleiras. Maceió: Sindicato da Indústria e do Álcool do Estado de Alagoas, 1998. 438p.

Caputo, M. M.; Silva, M. A.; Beauclair, E. G. F.; Gava, G. J. C. Acúmulo de sacarose, produtividade e florescimento de canade-açúcar sob reguladores vegetais. Interciência, v.32, n.12, p.834-840, 2007.

Carrijo, O. A.; Sousa, R. B.; Marouelli, W. A.; Andrade R. J. Circular Técnica 32: Fertirrigação de hortaliças. Brasília: EMBRAPA, 2004. 13p.

CONSECANA - Conselho dos Produtores de Cana-de-Açúcar, Açúcar e Álcool do Estado de São Paulo. Circular no 13/ 01, 2001.
CRSPCTS/PB - Comissão Regional do Sistema de Pagamento de Cana pelo Teor de Sacarose no Estado da Paraíba. Manual técnico operacional. João Pessoa, ed.4, 1997. 238p.

Dantas Neto, J.; Figueredo, J. L. da C., Farias, C. H. de A.; Azevedo, H. M. de; Azevedo, C. A. V. de. Resposta da cana-de-açúcar, primeira soca, a níveis de irrigação e adubação de cobertura. Revista Brasileira de Engenharia Agrícola e Ambiental, v.10, n.2, p.283-288, 2006.

Doorembos, J.; Kassam, A.H. Yield response to water. Rome: FAO. 1979. 193p. Irrigation and Drainage Paper 33.

EMBRAPA - Empresa Brasileira de Pesquisa Agropecuária. Centro Nacional de Pesquisa de Solos. Sistema brasileiro de classificação de solos. Brasília: Embrapa - Serviço de Produção de Informação, 1999. 412p.

Farias, C. H. de A.; Dantas Neto, J.; Fernandes, P. D.; Gheyi, H. R. Índice de área foliar em cana-de-açúcar sob diferentes níveis de irrigação e zinco na Paraíba. Caatinga, v.20, n.4, p.4555, 2007.

Gomes, F. P. Curso de estatística experimental. Piracicaba: Livraria Nobel Editora, 14.ed., 2000. 477p.

Leite, G. H. P. Maturação induzida, alterações fisiológicas, produtividade e qualidade tecnológica da cana-de-açúcar (Saccharum officinarum L.). Botucatu: UNESP, 2005. 141p. Tese Doutorado

Molinari, H. B. C.; Marur, C. J.; Daros, E.; Campos, M. K. F.; Carvalho, J. F. R. P.; Bespalhok Filho, J. C.; Pereira, L. F. P.; Vieira, L. G. E. Evaluation of the stress-inducible production of proline in transgenic sugarcane (Saccharum spp.): Osmotic adjustment, chlorophyll fluorescence and oxidative stress. Physiologia Plantarum, v.130, n.2, p.218-225, 2007.

Moura, M. V. P. da S.; Farias, C. H. de A.; Azevedo, C. A. V. de; Neto, J. D.; Azevedo, H. M. de; Pordeus, R. V. Doses de adubação nitrogenada e potássica em cobertura na cultura da canade-açúcar, primeira soca, com e sem irrigação. Ciência e Agrotecnologia, v.29, n.4, p.753-760, 2005.

Nunes Jr., D.; Pinto, R. S. A.; Kil, R. A. Indicadores de desempenho da agroindústria canavieira: safra 2002/2003. Brasília: Grupo IDEA, 2003. 95p.

Orlando Filho, J. Calagem e adubação da cana de açúcar. In: Câmara, G. M. S.; Oliveira, E. A. M. (ed). Produção de cana-deaçúcar. Piracicaba: FEALQ/USP, 1993. p.133-146.

Orlando Filho, J.; Zambelo Júnior; Haag, H. P. Absorção e remoção de zinco pela cana-de-açúcar, variedade CB 4176 em três solos do Estado de São Paulo. Brasil Açucareiro, v.1, n.96, p.31-41, 1980.

Ribeiro Junior, J.I. Análises estatística no SAEG. Viçosa: UFV. 2001, 301p.

RIDESA - Rede Interuniversitária para o Desenvolvimento do Setor Sucroalcooleiro. Programa de melhoramento genético da cana-de-açúcar: Variedades RB. Recife: UFRPE/EECA, 2003. 256p. Relatório anual

Robertson, M. J.; Donaldson, M. J. Changes in the components of cane and sucrose yield in response to drying-off before harvest. Field Crop Research, v.55, p.201-208, 1998.

Robertson, M. J., Inmam-Bamber, N. G.; Muchow, R. C.; Wood, A. W. Physiology and productivity of sugar cane with early and mid-season water deficit. Field Crop Research, v.64, p.211-227, 1999. 
Santos, G. C. G.; Abreu, C. A.; Camargo, O. A.; Abreu, M. F. Pó-de-aciaria como fonte de zinco para o milho e seu efeito na disponibilidade de metais pesados. Bragantia, v.61, n.3, p.257-266, 2002.

Silva, C. L. A.; Ramos, M. M.; Ferreira, P. A.; Sediyama, G. C.; Loureiro, B. T. Modelagem da precipitação efetiva na cultura do milho. Pesquisa Agropecuária Brasileira, v.29, n.6, p.929-937, 1994.

Taiz, L.; Zeiger, E. Plant physiology. Redwood City: Benjamin/ Cummings, 2004. 565p.
Valsechi, O. A. Pagamento de cana pelo teor de sacarose: O sistema implantado em São Paulo. Brasil Açucareiro, v.101, n.1/3, p.32-39, 1983.

Vitti, G. C. Nutrição e adubação da cana-de-açúcar. In: Curso Agrícola: Uso eficiente de fertilizantes na cana-de-açúcar. Araçatuba: UFSCar, 2003. 28p.

Wiedenfeld, R. P. Effects of irrigation and $\mathrm{N}$ fertilizer application on sugar cane yield and quality. Field Crop Research, v.43, p.101-108, 1995.

Wiedenfeld, R. P. Water stress during different sugar cane growth periods on yield and response to $\mathrm{N}$ fertilizer. Agriculture Water Management, v.43, p.173-182, 2000. 